\title{
Influence of temperature and carbon dioxide levels on growth and development of Spodoptera litura Fabricius on cauliflower
}

\section{TEJINDER SINGH BRAR and SMRITI SHARMA}

\author{
Department of Entomology, Punjab Agricultural University, Ludhiana- 141 004, India \\ *Corresponding author Email: smritisharma80@pau.edu
}

\begin{abstract}
The studies on influence of temperature and carbon dioxide levels on growth and development of Spodoptera litura on cauliflower were conducted with six different temperature and carbon dioxide regimes viz. $25: 11^{\circ} \mathrm{C}$ and $25: 14^{\circ} \mathrm{C}$ at $350,400,450 \mathrm{ppm}$ carbon dioxide concentrations. Observations on different biological indices were recorded to estimate the influence of elevated temperature and carbon dioxide on growth and development of $S$. litura. The study revealed temperature and carbon dioxide had significant effect on developmental indices of $S$. litura. It was observed that incubation period, larval duration, pupal duration, male adult longevity, female adult longevity decreased from 4.5, 23.4, 9.3, 6.8, 7.5, respectively at $25: 11^{\circ} \mathrm{C}$ to $3.9,21.2,8.7,6.5,7.4$ days respectively, at $25: 14^{\circ} \mathrm{C}$. Whereas fecundity of $S$ litura increased from 363.6 to 420.9 with increase in temperature and carbon dioxide indicating reduced generation time which could lead to more number of generations per year.
\end{abstract}

Keywords: Spodoptera litura, biology, developmental indices, temperature, carbon dioxide, cauliflower.

Climate change is now a days a major environmental concern that affects most ecosystems globally and is manifested as change in climate over a period of time due to natural variability or anthropogenic activity which has been a major cause of concern. It has also been reported that mean surface temperature has increased globally since the $19^{\text {th }}$ century with $0.73^{\circ} \mathrm{C}$ increase between the periods of 1850 1990 and 2003-2012 (IPCC 2013) and similarly the amount of carbon dioxide in the atmosphere has shown about 40 per cent elevation over pre industrial levels (IPCC 2013) and these levels of $\mathrm{CO}_{2}$ have been further expected to increase upto 405-460 ppm, 445-640 ppm and 540-970 ppm by 2025, 2050 and 2100 respectively (IPCC 2007). Climate change projections made for India indicated an overall increase in temperature from 2 to $4^{\circ} \mathrm{C}$ without any substantial change in precipitation by 2100 (Kumar et al., 2011). Studies in Punjab have also revealed that the mean minimum temperature has been increasing steadily since 1970, with estimated annual increase of $0.06^{\circ} \mathrm{C}$ without a significant change in maximum temperature (Kaur et al., 2013). Increased levels of $\mathrm{CO}_{2}$ could bring about qualitative and quantitative changes in the agricultural, horticultural and forest plants that could alter the abundance and distribution pattern of insect pest species (Kiritani 2006). The tobacco caterpillar, Spodoptera litura Fabricius (Lepidoptera: Noctuidae) is polyphagous pest, damaging more than 290 species of plants (Wu et al., 2004, Dhaliwal et al., 2010, Dalal and Arora 2016) including many economically important vegetables and ornamental plants. The temperature rise of $2.7-4.7^{\circ} \mathrm{C}$ predicted due to potential climate change may have drastic consequences for future incidence of $S$. litura (IPCC 2013). Hence present studies aimed to understand the effect of elevated concentrations of $\mathrm{CO}_{2}$ coupled with alternating temperature conditions on biological parameters of $S$. litura on cauliflower.

\section{MATERIALAND METHODS}

\section{Rearing of the test insect}

The initial culture of S. litura was collected from cabbage and cauliflower fields and these field collected larvae were reared in jars under laboratory conditions and fresh and cleaned cauliflower leaves were provided as food. The top of the jars were covered with a muslin cloth and the same was secured in position with the help of rubber bands. Food and blotting paper were changed daily to maintain hygiene. The full grown larvae which were about to pupate were transferred to other jars which had $6 \mathrm{~cm}$ thick layer of moist soil to facilitate pupation. The pupae were collected after 3 days of pupation and transferred to other set of jars for adult emergence. The pupae were surface sterilized by treating 0.025 per cent sodium hypochlorite solution and transferred to jars with a moistened foam disc ( $14 \mathrm{~mm}$ thick) at the bottom to prevent desiccation. Newly emerged male and female were kept together in jars $(25 \times 15 \mathrm{~cm})$ for mating and oviposition and 10 per cent of sugar solution was provided as food to the adults along with leaves for 
Table 1: Effect of changes intemperature and carbon dioxide concentrations on different biological parameters of $S$. litura

\begin{tabular}{|c|c|c|c|}
\hline \multirow{2}{*}{$\begin{array}{l}\text { Carbon dioxide } \\
\text { concentration (ppm) }\end{array}$} & \multicolumn{3}{|c|}{ Temperature, $\left(\right.$ Max: Min) ${ }^{\circ} \mathrm{C}$} \\
\hline & $25: 11(19.2)^{* *}$ & $25: 14(20.4)^{* *}$ & Mean \\
\hline \multicolumn{4}{|c|}{ Incubation period (days)* } \\
\hline 350 & $4.8 \pm 0.4(4-6)$ & $4.4 \pm 0.3(4-5)$ & $4.6 \pm 0.3$ \\
\hline 400 & $4.5 \pm 0.3(4-5)$ & $3.7 \pm 0.4(3-5)$ & $4.1 \pm 0.3$ \\
\hline 450 & $4.3 \pm 0.5(3-6)$ & $3.7 \pm 0.3(3-4)$ & $4.0 \pm 0.4$ \\
\hline Mean & $4.5 \pm 0.4$ & $3.9 \pm 0.3$ & \\
\hline \multicolumn{4}{|c|}{$\mathrm{CD}(\mathrm{p}=0.05) ; \mathrm{CO}_{2}$ conc. : NS; Temperature : NS; $\mathrm{CO}_{2}$ conc. $\mathrm{x}$ temperature $: \mathrm{NS}$} \\
\hline \multicolumn{4}{|c|}{ Total larval duration (days)* } \\
\hline 350 & $25.2 \pm 0.4(24-26)$ & $23.1 \pm 0.5(22-24)$ & $24.2 \pm 0.7$ \\
\hline 400 & $23.4 \pm 0.5(22-25)$ & $21.3 \pm 0.5(20-22)$ & $22.4 \pm 0.7$ \\
\hline 450 & $21.5 \pm 0.3(21-22)$ & $19.1 \pm 0.6(18-21)$ & $20.3 \pm 0.7$ \\
\hline Mean & $23.4 \pm 0.8$ & $21.2 \pm 0.9$ & \\
\hline \multicolumn{4}{|c|}{$\mathrm{CD}(\mathrm{p}=0.05) ; \mathrm{CO}_{2}$ conc. : $0.9 ;$ Temperature $: 0.8 ; \mathrm{CO}_{2}$ conc. $\mathrm{x}$ temperature $: \mathrm{NS}$} \\
\hline \multicolumn{4}{|c|}{ Pupal duration (days)* } \\
\hline 350 & $9.6 \pm 0.4(9-11)$ & $9.3 \pm 0.3(9-10)$ & $9.5 \pm 0.3$ \\
\hline 400 & $9.5 \pm 0.3(9-10)$ & $8.6 \pm 0.4(7-9)$ & $9.1 \pm 0.4$ \\
\hline 450 & $8.8 \pm 0.2(8-9)$ & $8.3 \pm 0.4(7-9)$ & $8.6 \pm 0.3$ \\
\hline Mean & $9.3 \pm 0.3$ & $8.7 \pm 0.4$ & \\
\hline \multicolumn{4}{|c|}{$\mathrm{CD}(\mathrm{p}=0.05) ; \mathrm{CO}_{2}$ conc. : $0.7 ;$ Temperature : $0.6 ; \mathrm{CO}_{2}$ conc. $\mathrm{x}$ temperature $:$ NS } \\
\hline
\end{tabular}

Values are Mean \pm SE of four replications, Figures in the parentheses denotes the range, ${ }^{*}$ These temperatures were maintained for 14:10 $\mathrm{h}$ with same duration of $\mathrm{L}: \mathrm{D}$ at constant $\mathrm{RH} 65 \pm 5 \%,{ }^{*}$ Figures in parentheses represent mean value of temperatures

oviposition (modified from Rao et al 2012). The jars were covered with muslin cloth and fastened with rubber bands to prevent escape of adults and provide aeration to adults. The adults that emerged on the same day were kept in same jars for continuation of egg laying. The insect culture was maintained throughout the study period to get continuous supply of sufficient number of insects. The glassware used in the experiments was thoroughly washed in detergent, treated with 2 per cent formalin and then dried in an oven at $30^{\circ} \mathrm{C}$ for 8 hours to check microbial contamination in the insect culture.

The present studies were carried out in Controlled Environment Chamber (PGW-40, M/s Percival Scientific, Inc., USA), Department of Entomology, Punjab Agricultural University, Ludhiana during the year 2015-16 to observe the effect of temperature and carbondioxide regimes on the development of $S$. litura. To achieve this objective different temperature and carbon dioxide combinations viz. $25: 11^{\circ} \mathrm{C}$ and $350 \mathrm{ppm}\left(\mathrm{T}_{1}\right), 25: 11^{\circ} \mathrm{C}$ and $400 \mathrm{ppm}\left(\mathrm{T}_{2}\right), 25: 11^{\circ} \mathrm{C}$ and $450 \mathrm{ppm}\left(\mathrm{T}_{3}\right), 25: 14^{\circ} \mathrm{C}$ and $350 \mathrm{ppm}\left(\mathrm{T}_{4}\right), 25: 14^{\circ} \mathrm{C}$ and 400
$\operatorname{ppm}\left(\mathrm{T}_{5}\right), 25: 14^{\circ} \mathrm{C}$ and $450 \mathrm{ppm}\left(\mathrm{T}_{6}\right)$ along with $14: 10$ photoperiod, $65 \pm 5$ per cent relative humidity were maintained. Twenty five first instar larvae per replication were transferred using a camel hairbrush in sample containers in four replications and reared on cauliflower leaves. A set of additional larvae were maintained under similar set of conditions to replace dead larvae.

\section{Statistical analysis}

The data were analyzed for Mean \pm SE and then subjected statistically as per completely randomized design (CRD) using computer programme CPCS1(Cheema and Singh 1993).

\section{RESULTS AND DISCUSSION}

\section{Lncubation period}

The incubation period of $S$. litura recorded at two alternating temperatures i.e $20: 11^{\circ} \mathrm{C}$ and $25: 14^{\circ} \mathrm{C}(14: 10$ photoperiod) and carbon dioxide i.e. 350,400 and $450 \mathrm{ppm}$ are presented in Table 1. Highest mean value of incubation period (4.6 \pm 0.3 days) was observed at $350 \mathrm{ppm} \mathrm{CO}_{2}$ level 
Table 2:Effect of change in temperature and carbon dioxide concentrations on the adult longevity (female) of S. litura

\begin{tabular}{lccc}
\hline $\begin{array}{l}\text { Carbon dioxide } \\
\text { concentration }(\mathrm{ppm})\end{array}$ & $25: 11(19.2)^{* *}$ & $\begin{array}{c}\text { Temperature, }(\text { Max: Min })^{\circ} \mathrm{C}^{*} \\
25: 14(20.4)^{* *}\end{array}$ & Mean \\
\hline $\begin{array}{l}\text { Adult longevity (female) (days) } \\
350\end{array}$ & $8.6 \pm 0.6(7-10)$ & $8.6 \pm 1.0(7-9)$ & $8.6 \pm 0.4$ \\
400 & $7.5 \pm 0.8(7-9)$ & $7.4 \pm 0.9(6-8)$ & $7.4 \pm 0.3$ \\
450 & $6.3 \pm 1.1(5-8)$ & $6.2 \pm 0.8(5-7)$ & $6.3 \pm 0.3$ \\
Mean & $7.5 \pm 1.1$ & $7.4 \pm 0.9$ &
\end{tabular}

$\mathrm{CD}(\mathrm{p}=0.05) ; \mathrm{CO}_{2}$ conc. : 0.9 ; Temperature : $\mathrm{NS} ; \mathrm{CO}_{2}$ conc. $\mathrm{x}$ temperature : NS

Adult longevity (male) (days)

$\begin{array}{lccc}350 & 7.5 \pm 0.5(6-9) & 7.1 \pm 0.4(6-8) & 7.3 \pm 0.4 \\ 400 & 6.5 \pm 0.4(6-8) & 6.2 \pm 0.5(5-8) & 6.4 \pm 0.4 \\ 450 & 6.3 \pm 0.6(5-8) & 6.3 \pm 0.3(5-7) & 6.3 \pm 0.5 \\ \text { Mean } & 6.8 \pm 0.5 & 6.5 \pm 0.4 & \end{array}$

$\mathrm{CD}(\mathrm{p}=0.05) ; \mathrm{CO}_{2}$ conc. : 0.9 ; Temperature : NS; $\mathrm{CO}_{2}$ conc. $\mathrm{x}$ temperature : NS

Adult emergence (percentage)

$\begin{array}{lccr}350 & 77.9 \pm 0.7(76.2-79.7) & 89.4 \pm 0.8(87.5-91.1) & 83.6 \pm 3.1 \\ 400 & 86.3 \pm 0.5(84.5-87.2) & 93.7 \pm 0.6(92.1-94.9) & 90.0 \pm 2.0 \\ 450 & 81.8 \pm 0.6(80.3-83.3) & 92.3 \pm 0.9(90.1-94.6) & 87.1 \pm 2.9 \\ \text { Mean } & 82.0 \pm 1.9 & 91.8 \pm 1.2 & \\ \mathrm{CD}(\mathrm{p}=0.05) ; \mathrm{CO}_{2} \text { conc. : NS; Temperature : } 7.73 ; \mathrm{CO}_{2} \text { conc. } \mathrm{x} \text { temperature : NS } & \\ \text { Fecundity (eggs/female) } & & & \\ 350 & 363.6 \pm 1.0(360-365) & 374.3 \pm 2.8(367-382) & 368.9 \pm 3.2 \\ 400 & 395.3 \pm 1.6(394-399) & 411.9 \pm 3.1(405-422) & 403.6 \pm 4.2 \\ 450 & 414.1 \pm 4.4(405-430) & 420.9 \pm 3.7(420-444) & 417.5 \pm 4.1 \\ \text { Mean } & 391.0 \pm 5.8 & 402.4 \pm 5.6 & \end{array}$

$\mathrm{CD}(\mathrm{p}=0.05) ; \mathrm{CO}_{2}$ conc. : 12.2 ; Temperature : $9.9 ; \mathrm{CO}_{2}$ conc. $\mathrm{x}$ temperature $: \mathrm{NS}$

Values are Mean $\pm \mathrm{SE}$ of four replications, Figures in the parentheses denotes the range, ${ }^{*}$ These temperatures were maintained for 14:10 $\mathrm{h}$ with same duration of $\mathrm{L}: \mathrm{D}$ at constant $\mathrm{RH} 65 \pm 5 \%, * *$ Figures in parentheses represent mean value of temperatures.

and lowest duration (4.0 \pm 0.4 days) was observed at 450 ppm $\mathrm{CO}_{2}$ with intermediate ( $4.1 \pm 0.3$ days $)$ at $400 \mathrm{ppm} \mathrm{CO}_{2}$. Highest (4.5 \pm 0.4 days) duration of incubation was observed at $25: 11^{\circ} \mathrm{C}$ and lowest duration ( $3.9 \pm 0.3$ days) was observed at 25:14 C. It was observed that there was no significant effect of temperature, carbon dioxide and their interaction on the incubation period of S. litura. The results are in accordance with earlier reports of incubation period of $S$. litura to vary from 4.3 days (Vashisht et al., 2012) to 5.6 days (Soni et al., 2011).

\section{Total larval duration}

Total larval duration was higher (23.4 \pm 0.8 days) at
$25: 11^{\circ} \mathrm{C}$ and lower $(21.2 \pm 0.9$ days $)$ at $25: 14^{\circ} \mathrm{C}$. Similartly, highest duration (24.2 \pm 0.7 days) was recorded at $350 \mathrm{ppm}$ and minimum duration (20.3 \pm 0.7 days $)$ at $450 \mathrm{ppm}$ concentration (Table 1). Bumpy (2016) and Akbar et al., (2015) also reported decrease in larval duration of $P$. brassicase and $\mathrm{H}$. armigera under elevated $\mathrm{CO}_{2}$. Moreover, statistically, significant difference was observed in our study both under elevated temperature and elevated $\mathrm{CO}_{2}$ conditions. While, interactive effect of temperature and $\mathrm{CO}_{2}$ regimes was observed to be non significant. The results of present study are in coherence with earlier studies by Kumari (2016). 


\section{Pupal duration}

The pupal period of $S$. litura at alternating temperatures of $20: 11^{\circ} \mathrm{C}$ and $25: 14^{\circ} \mathrm{C}$ and carbon dioxide i.e. 350,400 and 450 ppm was observed to vary with change in both temperature and $\mathrm{CO}_{2}$ (Table 1$)$. The mean duration of $9.5 \pm 0.3,9.1 \pm 0.4,8.6 \pm 0.3$ was recorded at $350,400,450$ ppm $\mathrm{CO}_{2}$ concentration and $9.3 \pm 0.3,8.7 \pm 0.4$ days under temperature conditions of $25: 11^{\circ} \mathrm{C}$ and $25: 14^{\circ} \mathrm{C}$, respectively. Significant effect of temperature was observed on the pupal period of $S$. litura with longest duration (9.3 \pm 0.3 days) at $25: 11^{\circ} \mathrm{C}$ and shortest duration $(8.7 \pm 0.4$ days) at $25: 14^{\circ} \mathrm{C}$. Similarly, longest duration ( $9.5 \pm 0.3$ days) was recorded at $350 \mathrm{ppm} \mathrm{CO} \mathrm{CO}_{2}$ concentration and shortest ( $8.6 \pm 0.3$ days) at 450 ppm $\mathrm{CO}_{2}$ concentration. Similar results were reported by Bumpy (2016) who also reported pupal duration was maximum $36.3 \pm 1.9$ days at $20: 10^{\circ} \mathrm{C}$ and minimum $10.5 \pm 0.3$ days at $35: 25^{\circ} \mathrm{C}$. The pupal duration decreased with increased temperature and these differences were statistically significant under elevated $\mathrm{CO}_{2}$ conditions. The duration of $S$. litura at $400 \mathrm{ppm} \mathrm{CO}_{2}$ was at par with its duration at $450 \mathrm{ppm} \mathrm{CO}_{2}$ which showed significant difference with duration at $350 \mathrm{ppm} \mathrm{CO}_{2}$. The duration at $25: 11^{\circ} \mathrm{C}$ was at par with the duration at $25: 14^{\circ} \mathrm{C}$. While, interactive effect of temperature and $\mathrm{CO}_{2}$ regimes was observed to have non significant effect on total larval duration of S. litura.

\section{Adult longevity}

The mean female longevity of $S$. litura at various regimes of alternating temperatures i.e $20: 11^{\circ} \mathrm{C}, 25: 14^{\circ} \mathrm{C}$ and carbon dioxide 350,400 and $450 \mathrm{ppm}$ was observed to be affected by temperature and $\mathrm{CO}_{2}$ (Table 2). The mean female longevity of $8.6 \pm 0.4,7.4 \pm 0.3$ and $6.3 \pm 0.3$ was recorded at 350,400 and $450 \mathrm{ppm} \mathrm{CO}_{2}$ concentration. Mean longevity of $7.5 \pm 1.1$ and $7.4 \pm 0.9$ days was recorded under temperature conditions of $25: 11^{\circ} \mathrm{C}$ and $25: 14^{\circ} \mathrm{C}$ respectively. The mean female longevity was significantly affected by carbon dioxide with highest $(8.6 \pm 0.4$ days) duration at $350 \mathrm{ppm}$ and decreased to $6.3 \pm 0.3$ days duration with increase of $100 \mathrm{ppm} \mathrm{CO}_{2}$. While with $3^{\circ} \mathrm{C}$ increase in minimum temperature from 11 to $14^{\circ} \mathrm{C}$ resulted in decrease in mean female longevity from $7.5 \pm 1.1$ to $7.4 \pm 0.9$ days but statistically the effect was non significant. But, significant differences were observed under elevated $\mathrm{CO}_{2}$ conditions. Whereas, effect of temperature and its interactive effect with $\mathrm{CO}_{2}$ regimes was observed to be non significant. Similar trend in adult female longevity was also observed by Bumpy (2016) who reported that female longevity decreased with increase in $\mathrm{CO}_{2}$ concentration from 300 to $500 \mathrm{ppm}$ and also decreased with increase in alternating temperature from $25: 10$ to $30: 13^{\circ} \mathrm{C}$.

Similarly in case of mean male longevity significant effect was recorded due to increase in carbon dioxide concentration with maximum mean male longevity $(7.3 \pm 0.4$ days) at $350 \mathrm{ppm}$ and lowest (6.3 \pm 0.5 days) at $450 \mathrm{ppm}$. While, with the increase of temperature from $25: 11$ to $25: 14^{\circ} \mathrm{C}$ the mean longevity of adult males decreased from $6.8 \pm 0.5$ to $6.5 \pm 0.4$ days. Statistically, significant differences were observed under elevated $\mathrm{CO}_{2}$ conditions but the duration at $400 \mathrm{ppm} \mathrm{CO}_{2}$ was at par with duration at $450 \mathrm{ppm}$ $\mathrm{CO}_{2}$. On the contrary, effect of temperature and its interactive effect with $\mathrm{CO}_{2}$ regimes was observed to be non significant (Table 2). When compared to female longevity, male longevity was found to be lower in the present findings. These results were found to be in agreement with the studies done by Rosaiah and Reddy (1999). These results are also in accordance to the findings of Bumpy (2016) who reported longest male longevity of $H$. armigera of 16.4 days at the lower temperature $20: 10^{\circ} \mathrm{C}$ and shortest 7.4 days at $30: 20^{\circ} \mathrm{C}$.

It was observed that mean per cent adult emergence was more at elevated alternating temperature of $25: 14^{\circ} \mathrm{C}$ (91.8) as compared to $25: 11^{\circ} \mathrm{C}(82.0)$. Also, the mean emergence of adults was highest at ambient $\mathrm{CO}_{2}$ concentration of $400 \mathrm{ppm}$ (90.0) followed by $450 \mathrm{ppm}$ (87.1) and $350 \mathrm{ppm}$ (83.6), while decrease in $\mathrm{CO}_{2}$ led to decrease in per cent adult emergence. The effect of $\mathrm{CO}_{2}$ and its interaction with temperature was statistically non significant while temperature exerted significant effect and with $3^{\circ} \mathrm{C}$ rise in temperature the emergence was significantly affected (Table 2). These results are in agreement with the findings of Bumpy (2016) who reported no significant effect of $\mathrm{CO}_{-}$on per cent adult emergence of $P$. brassicae. The results of present study are in contrast to those reported by Akbar et al., (2015) on H. armigera, that the adult emergence values were low at $350 \mathrm{ppm}$ as compared to 550 ppm. The duration of life cycle was observed to decrease with increase in carbon dioxide concentration with highest (46.8 days) duration at $350 \mathrm{ppm}$ and lowest (39.1 days) at $450 \mathrm{ppm}$. While, with increase in temperature from $25: 11^{\circ} \mathrm{C}$ to $25: 14^{\circ} \mathrm{C}$ duration of life cycle decreased from 44.7 to 41.2 days.

\section{Fecundity}

Temperature and carbon dioxide showed significant effect on fecundity of $S$. litura (Table 2). The highest mean fecundity $\left(402.4 \pm 5.6\right.$ eggs female $\left.{ }^{-1}\right)$ was recorded at $25: 14^{\circ} \mathrm{C}$ 
and lowest fecundity of $391 \pm 5.8$ eggs per female was recorded at $25: 11^{\circ} \mathrm{C}$. Similarly, highest mean fecundity of $417.5 \pm 4.1$ eggs per female was recorded at $450 \mathrm{ppm} \mathrm{CO}_{2}$, followed by $403.6 \pm 4.2$ eggs per female at $400 \mathrm{ppm}$ and $368.9 \pm 3.2$ eggs per female were recorded at $350 \mathrm{ppm} \mathrm{CO}_{2}$ concentration. These results are in agreement with the findings of Akbar et al (2015) where female fecundity of $H$. armigera was significantly higher when larvae were reared at $750 \mathrm{ppm} \mathrm{CO}_{2}\left(1293 \mathrm{eggs} \mathrm{female}^{-1}\right)$ as compared to that at 350 and $550 \mathrm{ppm} \mathrm{CO}_{2}$ (831 and 824 eggs female ${ }^{-1}$, respectively). In present study, significant differences were observed with increase in minimum temperature from 11 to $14^{\circ} \mathrm{C}$ with higher mean no of eggs per female $(402.4 \pm 5.6)$ were recorded at $25: 14^{\circ} \mathrm{C}$ as compared to $25: 11^{\circ} \mathrm{C}(391 \pm 5.8$ eggs female $\left.{ }^{-1}\right)$. Similarly the effect of $\mathrm{CO}_{2}$ was also observed to be significant and the increase or decrease in $\mathrm{CO}_{2}$ to 450 and $300 \mathrm{ppm}$ respectively led to a significant increase and decrease in mean no of eggs laid per female of S. litura. The effect of interaction of temperature and $\mathrm{CO}_{2}$ was observed to be non significant. Similar results were observed in findings of Bumpy (2016) who reported highest number of eggs of P. brassicae (46.1 eggs per female) at the higher temperature regime of $30: 13^{\circ} \mathrm{C}$ and the least $(24.6$ eggs per female) at the lower temperature regime of $25: 10^{\circ} \mathrm{C}$.

\section{CONCLUSION}

In the present study, it was observed that incubation period, larval duration, pupal duration, male adult longevity and female adult longevity decreased with increase in temperature. Whereas fecundity of S litura increased with increase in temperature and carbon dioxide indicating reduced generation time which could lead to more number of generations per year. Hence it can be concluded that elevated temperature and $\mathrm{CO}_{2}$ affected the different biological parameters of $S$. litura resulting in more number of generations and ultimately increasing population pressure on crop.

\section{ACKNOWLEDGMENTS}

The authors are thankful to Head, Department of Entomology, Punjab Agricultural University, Ludhiana and Department of Science and Technology (DST), Government of India for providing financial assistance and equipments under Promotion of University Research and Scientific Excellence (PURSE) grant to conduct the research work.

\section{REFERENCES}

Akbar, S.M.D.,Pavani, T., Nagaraja, T. and Sharma,H.C.(2015). Influence of $\mathrm{CO}_{2}$ and temperature on metabolism and development of Helicoverpa armigera (Noctuidae: Lepidoptera). Environ. Ent., 11: 1-11.

Bumpy, K. (2016). Effect of varying levels of temperature and carbon dioxide on selected insect pests of vegetable crops. Ph.Ddissertation. PunjabAgricultural University, India.

Cheema H S and Singh B (1993). CPSC1: a programme package for the analysis of commonly used experimental designs. Punjab Agricultural University, Ludhiana, Punjab.

Dalal,P.K. and Arora, R. (2016). Impact of temperature on food consumption and nutritional indices of tomato fruit borer, Helicoverpa armigera (Hübner) (Noctuidae: Lepidoptera). J.Agrometeorol., 18:62-67.

Dhaliwal, G.S., Jindal, V. and Dhawan, A.K. (2010). Insect pest problems and crop losses: changing trends. Indian J. Ecol., 37:1-7.

IPCC (2007). Climate change 2007: Synthesis approach. www.ipcc.ch/pdf/assessment-report/ar4/syr/ ar4_syr_spm.pdf

IPCC (2013). The physical science basis. Summary for policy makers, Contribution of working group one to fifth assessment. Report of the intergovernmental panel on climate change. IPCCSecretriate, WMO, Geneva, Switzerland,pp 3.

Kaur, P., Sandhu, S.S., Singh, S. and Gill, K.K. (2013). “Climate change-Punjab scenario".Punjab University, Ludhiana, p 16.

Kiritani, K. (2006). Pridicting impacts of global warming on population dynamics and distribution of arthropods in Japan. Pop. Ecol., 48:5-12.

Kumar, K.K., Kamala, K., Rajagopalan, B., Hoerling, M.P., Eischeid, J.K., Patwardhan, S.K., Srinivasan, G., Goswami, B.N. and Nemani, R. (2011).The once and future pulse of Indian monsoonal climate.Clim. Dyn., 36: 2159-2170.

Kumari (2016)Studies onimpact of climate change on vegetable crop production in mid hills of Himachal Pradesh. Ph.D. dissertation. DrYashwant Singh Parmar University of Horticulture and Forestry, Solan (Nauni), India.

Rao, M.S., Manimanjari, D., Vanaja, M., Rao, C.A., Sriniva, K., Rao, V.U.M. and Venkateswarlu, B. (2012). Imapct of elevated $\mathrm{CO}_{2}$ on tobacco caterpillar, Spodoptera litura on peanut, Arachnis hypogea. J. Insect. Sci., 12:103106. 
Rosaiah, B. and Reddy, A.S. (1999). Bioecology of Helicoverpa armigera (Hubner) in Nagarjuna Sagar Project area of Andhra Pradesh. J. Insect. Sci., 12: 27-33.

Soni, V.K., Dixit, S.A. and Duby, V.K. (2011).Host-biology relation of Spodoptera litura (Fab.) (Lepidoptera: Noctuidae). Insect.Ent., 7:111-112.
Vashisht, S., Chandel, Y.S. and Kumar, S. (2012). Biology and damage potential of Spodoptera litura (Fab.) on some important greenhouse crops. J. Insect. Sci., 13:277279.

Wu, C.J., Fan, S.Y., Jiang, Y.H. and Zhang, A.B. (2004).Inducing gathering effect of taro on Spodoptera litura Fabricius. Chin. J. Ecol., 23:172-174.

Received: April 2017 ; Accepted: September 2017 